Research Paper

\title{
Small interfering RNA-induced silencing IncRNA PVT1 inhibits atherosclerosis via inactivating the MAPK/NF-KB pathway
}

\author{
Hong Du ${ }^{1}$, Hui Zhang ${ }^{1}$, Rong Yang ${ }^{1}$, Li Qiao ${ }^{1}$, Huiyu Shao ${ }^{1}$, Xiaolin Zhang ${ }^{1}$ \\ ${ }^{1}$ Department of Cardiology, Second Hospital of Hebei Medical University, Shijiazhaung 050000 Hebei, P.R. China
}

Correspondence to: Hong Du; email: drhongdu333@163.com, https://orcid.org/0000-0001-7015-904X

Keywords: atherosclerosis, human arterial vascular smooth muscle cells, MAPK/NF-KB pathway, PVT1, small interfering RNA

Received: February 2, $2021 \quad$ Accepted: October 25, $2021 \quad$ Published: November 13, 2021

Copyright: (C) 2021 Du et al. This is an open access article distributed under the terms of the Creative Commons Attribution License (CC BY 3.0), which permits unrestricted use, distribution, and reproduction in any medium, provided the original author and source are credited.

\section{ABSTRACT}

Atherosclerosis (AS) is a chronic disease of the arterial wall. The role of IncRNAs in AS has been acknowledged. This study investigated the role of IncRNA plasmacytoma variant translocation 1 (PVT1) in AS via the MAPK/NFKB pathway. Serum samples were collected from AS and non-AS patients. Serum levels of PVT1, CRP, IL-6, IL-1 $\beta$, and TNF- $\alpha$ were determined. AS mouse model was established and transfected with si-PVT1. Levels of TG, TC, HDL, LDL, MAPK, NF-KB, MMP-2, MMP-9, TIMP-1, and macrophage content were detected. Human arterial vascular smooth muscle cells (HA-VSMCs) induced by $50 \mathrm{mg} / \mathrm{mL}$ ox LDL were transfected with si-PVT1 or oe-PVT1 and added with MAPK inhibitor U0126. Viability, apoptosis, cell cycle, colony formation and DNA replication were assessed. Levels of apoptosis-related proteins were detected. Consequently, PVT1 was highly expressed in AS patients. Silencing PVT1 decreased levels of TG, TC, LDL, IL-6, IL-1 $\beta$, TNF- $\alpha$, MMP-2, MMP-9, CRP, TIMP-1, MAPK, and NF-KB, increased HDL, reduced atherosclerotic plaques and macrophage content in mice, inhibited viability, clones and EdU positive rates in HA-VSMCs, but promoted apoptosis and cell cycle arrest. Inhibition of MAPK/NF-KB pathway suppressed proliferation and promoted apoptosis of HA-VSMCs while PVT1 overexpression facilitated AS development. Briefly, silencing PVT1 inhibited AS development by downregulating MAPK/NF-KB pathway.

\section{INTRODUCTION}

Atherosclerosis (AS) is manifested with chronic inflammation and dysfunction in the vascular system, which may cause severe consequences such as sudden cardiac death, myocardial infarction, peripheral thromboses and stroke [1]. Generally, endothelial dysfunction interacts with subendothelial lipoprotein retention, which takes place mainly in the intima of moderate arteries, particularly bifurcation points and arteriolar bifurcations, when blood flows are blocked [2, 3]. Besides, the treatment approaches for AS include limiting the hazard factors like hyperlipemia or high blood pressure and regulating inflammatory responses, among which regulating inflammatory response is still under development in the blood vessels [4]. Therefore, it is necessary to attach great importance to developing novel intervention strategies for AS.
Long noncoding RNAs (lncRNAs), normally defined as a set of transcripts with the length of more than 200 nucleotides without any protein-coding ability [5], are engaged in manipulating diverse cellular processes [6], vascular wall function, macrophage activation, lipid metabolism and inflammatory responses [7]. The lncRNA plasmacytoma variant translocation 1 (PVT1), a RNA gene of the lncRNA class, acts as a diagnostic marker for type 2 diabetes and a contributor to tumor development [8]. LncRNA PVT1 functions as an independent hazard factor for coronary AS progression and is highly expressed in AS patients [9], but the exact mechanism is still unclear. Recently, compelling evidence reveals novel approaches for AS based on the combination of IncRNA VINAS and the mitogenactivated protein kinase (MAPK) or nuclear factor- $\kappa \mathrm{B}$ (NF- $\kappa B$ ) pathways [10]. Activating the $N F-\kappa B$ or MAPK pathway is responsible to some extend for 
inflammatory responses in ischemic stroke [11]. Yousif et al. (2018) have verified the cardioprotective effects exerted by the inactivation of the p38-MAPK/NF- $\kappa \mathrm{B}$ pathways with the involvement of Irbesartan against polymicrobial sepsis, a systemic inflammatory response usually correlated with several organ failures, possibly by attenuating myocardial dysfunction and reducing pro-inflammatory cytokines [12]. In addition, Pan (2017) has confirmed the critical function of lncRNA $\mathrm{H} 19$ in regulating AS through the MAPK and NF- $\kappa B$ pathways [13]. From above mentioned findings, it is reasonable to hypothesize the implication of IncRNA PVT1 and the MAPK/NF- $\kappa$ B signaling pathway in AS progression. Thus, we implemented a study to explore how IncRNA PVT1 acts on AS by regulating the MAPK/NF- $\kappa B$ pathway with the expectation to seek out novel clinical value for AS patients.

\section{RESULTS}

\section{PVT1 is highly expressed in AS patients}

We first detected PVT1 expression in the serum of $52 \mathrm{AS}$ patients and 32 healthy people by qRT-PCR. It was found that PVT1 expression in AS patients was significantly increased relative to that in healthy people (Figure 1A) $(p<0.05)$. Besides, AS is regarded as an inflammatory condition in the arterial wall. So, we measured the levels of IL- 6 , IL- $1 \beta$, and TNF- $\alpha$ in the serum of AS patients and healthy people with ELISA kits. The results demonstrated that levels of IL-6, IL-1 $\beta$ and TNF- $\alpha$ were substantially higher in AS patients than those in healthy people (Figure 1B) $(p<0.05)$.

\section{Silencing PVT1 reduces AS damage in ApoE-/-mice}

LncRNA PVT1 was reported to serve as an independent hazard factor in AS development and highly expressed in AS patients [9]. Therefore, the expression of PVT1 in mice was determined by qRT-PCR, which revealed that PVT1 expression in ApoE-/-mice was greatly elevated relative to that in wild $\mathrm{C} 57 \mathrm{BL} / 6 \mathrm{~J}$ mice fed with normal diet (Figure 2A) $(\mathrm{p}<0.05)$. After silencing PVT1, the serum levels of TG, TC, and LDL were significantly decreased and the serum level of HDL was elevated in ApoE-/-mice (Figure 2B) $(\mathrm{p}<0.05)$. The oil red O staining exhibited that the number and size of AS plaques in ApoE-/-mice were evidently decreased after silencing PVT1 (Figure 2C) $(\mathrm{p}<0.05)$. The results of qRT-PCR and Western blot analysis presented that levels of matrix metalloproteinase 2 (MMP-2), MMP-9, and CRP in AS plaques in ApoE-/-mice were notably decreased while levels of tissue inhibitor of metalloproteinase-1 (TIMP-1) were increased after silencing PVT1 (Figure 2D-2E) (all $\mathrm{p}<0.05$ ). ELISA results demonstrated that the levels of IL- 6 , IL- $1 \beta$ and TNF- $\alpha$ in ApoE-/-mice were obviously decreased (Figure 2F) $(\mathrm{p}<0.05)$, and immunohistochemistry showed macrophages in ApoE-/-mice were significantly reduced after silencing PVT1 (Figure 2G) $(p<0.05)$. Briefly, silencing PVT1 reduces AS damage in ApoE-/mice.
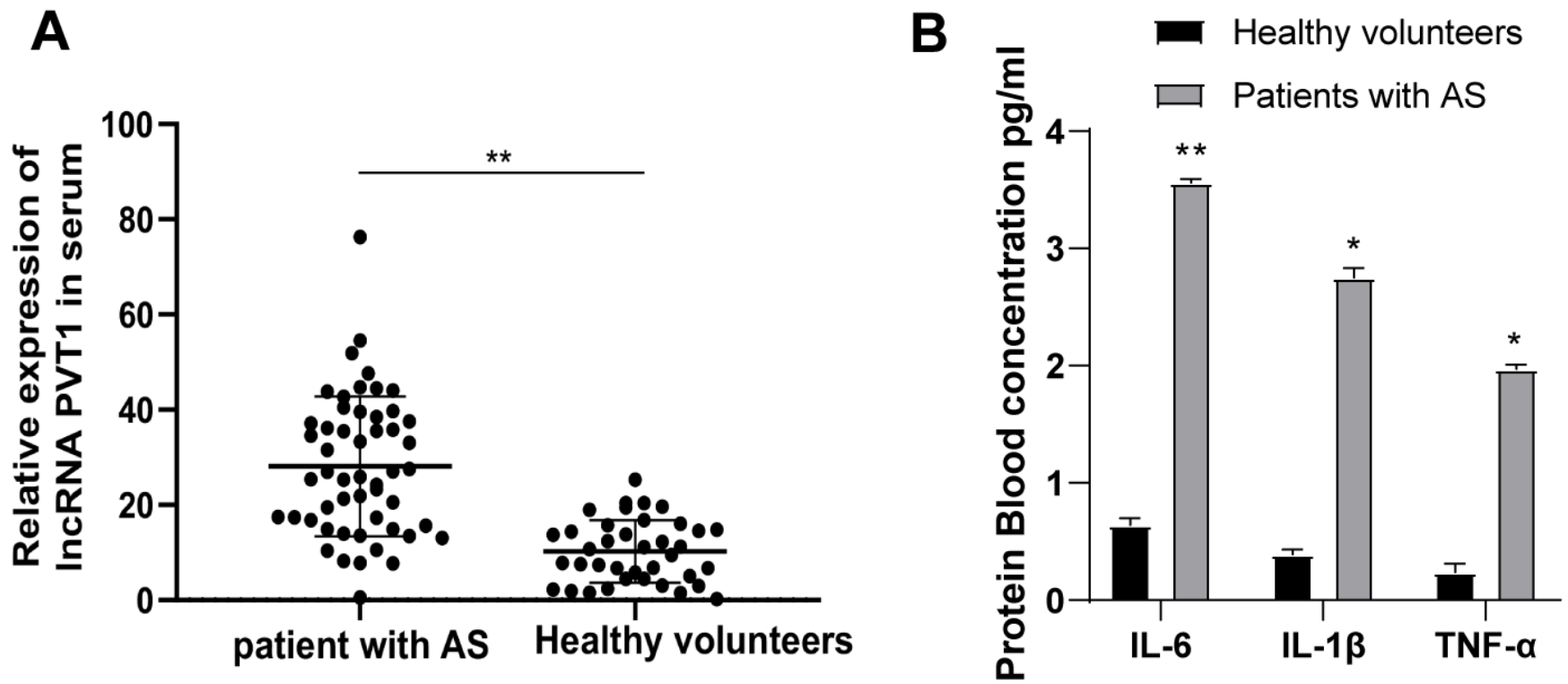

Figure 1. PVT1 is highly expressed in AS patients. (A) Relative PVT1 expression in serum of AS patients and healthy controls detected by qRT-PCR; (B) Levels of IL-6, IL-1 $\beta$ and TNF- $\alpha$ in serum of AS patients detected by ELISA. ${ }^{*} p<0.05,{ }^{* *} p<0.01$. PVT1, plasmacytoma variant translocation 1; AS, atherosclerosis; CRP, C-reactive protein; IL, interleukin; TNF- $\alpha$, tumor necrosis factor-alpha. 
PVT1 is highly expressed in oxLDL-treated HAVSMCs

HA-VSMCs were treated for $24 \mathrm{~h}$ with $50 \mathrm{mg} / \mathrm{mL}$ ox LDL. MTT assay showed enhanced viability of HA-VSMCs after ${ }_{\text {ox }}$ LDL treatment (Figure 3A) $(p<0.05)$. ELISA showed elevated levels of TG, TC and LDL and diminished HDL level in HA-VSMCs after ox LDL treatment (Figure 3B) $(p<0.05)$, indicating the presence of lipid metabolism disorder in HA-VSMCs after ox LDL treatment and successful establishment of AS cell model. The expression of PVT1 in oxLDL-treated HA-VSMCs was determined by qRT-PCR. We found highly expressed

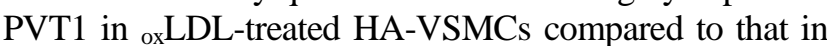

untreated cells (Figure 3C) $(p<0.05)$. These results elicited that PVT1 is highly expressed in ${ }_{\text {ox }} \mathrm{LDL}$-treated HA-VSMCs.

\section{Silencing PVT1 inhibits the viability and proliferation of HA-VSMCs}

The abnormal proliferation of VSMCs contributes to plaque formation [14-17]. To investigate the involvement of lncRNA PVT1 in the abnormal proliferation of oxLDL-induced VSMCs, oxLDLinduced VSMCs were transfected with oe-NC, oePVT1, si-NC and si-PVT1, respectively. Green fluorescence was observed after $48 \mathrm{~h}$ of transfection

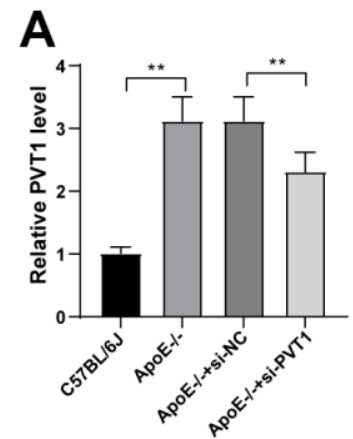

C

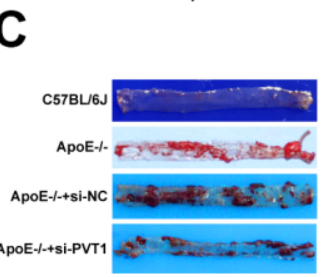

$\mathbf{F}$

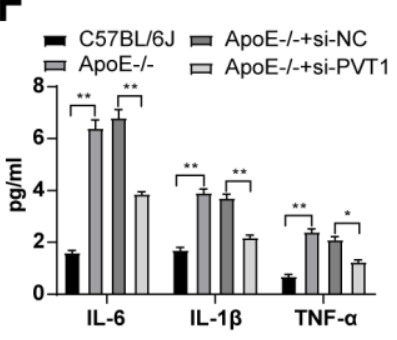

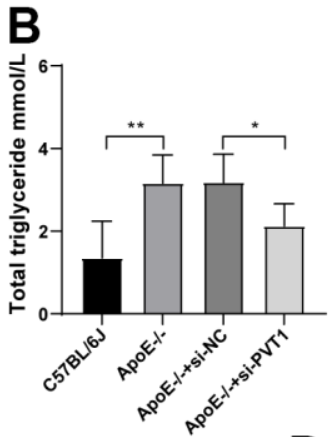
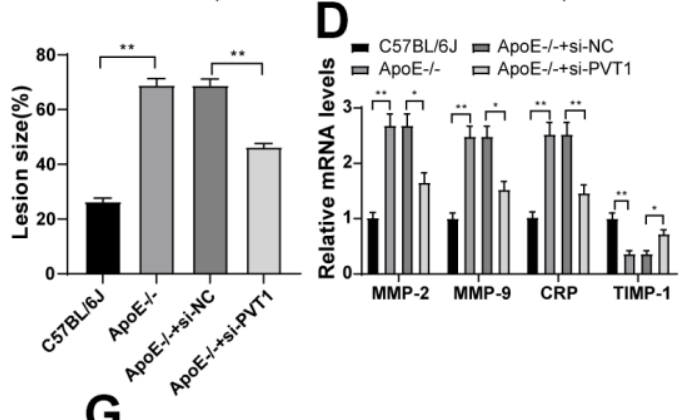
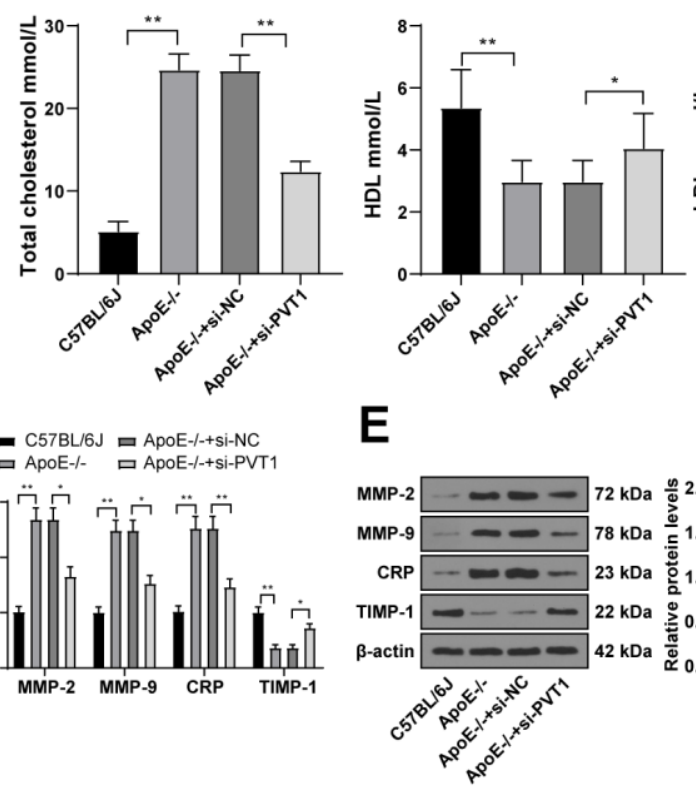
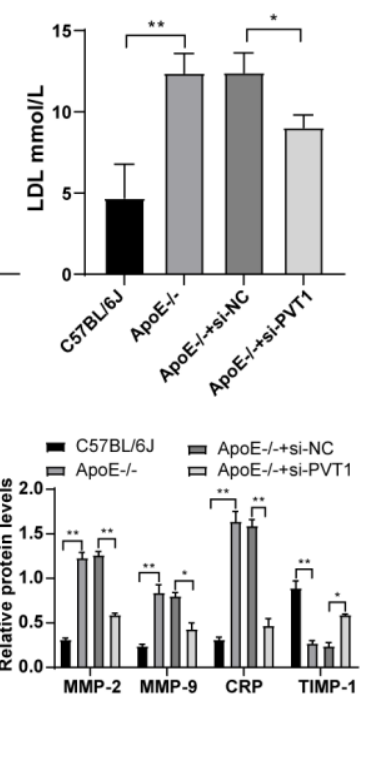
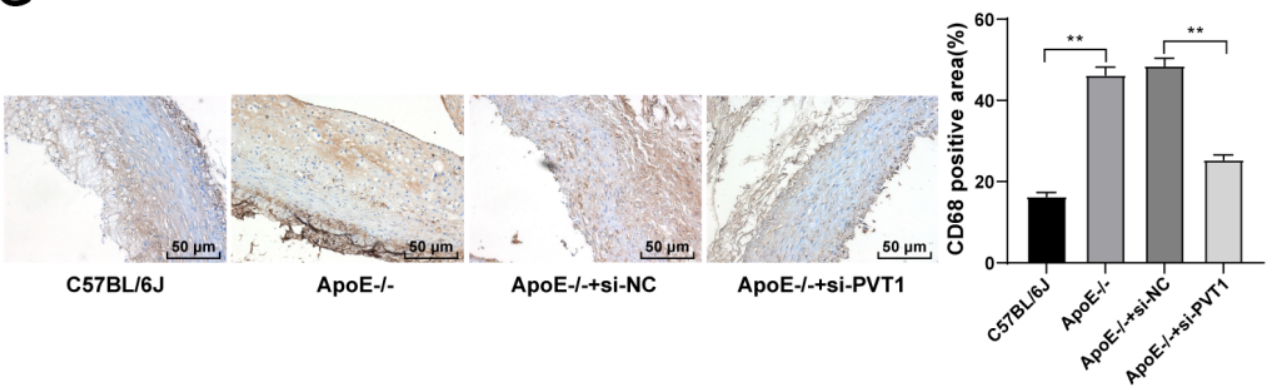

Figure 2. Silencing PVT1 reduces AS damage in ApoE-/- mice. ApoE-/- mice were fed with high-fat diet for 12 weeks. (A) Relative PVT1 expression in mice detected by qRT-PCR; (B) Levels of TG, TC, HDL, and LDL detected by ELISA; (C) Lipid accumulation on the aortic wall detected by oil red O staining; (D) mRNA levels of MMP-2, MMP-9, CRP, and TIMP-1 detected by qRT-PCR; (E) Protein levels of MMP-2, MMP9, CRP and TIMP-1 detected by Western blot; (F) Levels of IL-6, IL-1 $\beta$, and TNF- $\alpha$ detected by ELISA; (G) CD68 positive cells detected by immunohistochemistry. $N=6$. Data were presented as mean \pm standard deviation. Comparisons among multi-groups were analyzed using one-way ANOVA, followed by Tukey's multiple comparisons test. ${ }^{*} p<0.05,{ }^{*} p<0.01$. PVT1, plasmacytoma variant translocation 1 ; AS, atherosclerosis; ApoE-/-, apolipoprotein E knockout; TG, total triglyceride; TC, total cholesterol; HDL, high density lipoprotein; LDL, low density lipoprotein; MMP, matrix metalloproteinase; TIMP-1, tissue inhibitor of metalloproteinase-1; CRP, C-reactive protein; IL, interleukin; TNF- $\alpha$, tumor necrosis factor-alpha. 
(Figure 4A) $(\mathrm{p}<0.05)$, and the expression of PVT1 was verified by qRT-PCR (Figure 4B) $(\mathrm{p}<0.05)$. MTT assay indicated that the cell viability was notably facilitated at $24 \mathrm{~h}, 48 \mathrm{~h}$ and $72 \mathrm{~h}$ after PVT1 overexpression, and was obviously decreased after silencing PVT1 (Figure 4C) $(p<0.05)$. Colony formation assay showed clones were greatly increased after PVT1 overexpression, and were significantly decreased after silencing PVT1 (Figure 4D) $(p<0.05)$. EdU assay suggested that the positive rate of EdU was markedly augmented after PVT1 overexpression, and was decreased after silencing PVT1 (Figure 4E) (all $p<$ 0.05). Altogether, silencing PVT1 inhibits the viability and proliferation of VSMCs.

\section{Silencing PVT1 promotes apoptosis and cell cycle arrest of HA-VSMCs}

Furthermore, flow cytometry detected cell apoptosis and cell cycle, and showed less apoptotic cells with a large number of cells in S phase after PVT1 overexpression while apoptotic cells were significantly increased with diminished $S$ phase cells and augmented $\mathrm{G} 2 / \mathrm{M}$ phase cells after silencing PVT1 (Figure 5A, 5B) (all $p<0.05$ ). Western blot analysis was used to detect the levels of cell apoptotic-related proteins and the results showed decreased levels of cleaved caspase-3, poly(ADP-ribose) polymerase (PARP), and cleaved caspase-9 after PVT1 overexpression and increased levels of cleaved caspase-3, PARP, and cleaved caspase-9 after silencing PVT1 (Figure 5C) $(p<0.05)$. Collectively, silencing PVT1 promotes apoptosis and cell cycle arrest of VSMCs.
Silencing PVT1 downregulates the MAPK/NF-кB signaling pathway in ox LDL-treated HA-VSMCs and AS mice

PVT1 upregulation activates the MAPK/NF- $\kappa$ B pathway and promotes secretion of inflammatory factors while silencing PVT1 inhibits the the MAPK/ NF- $\kappa B$ pathway [18]. As the MAPK/NF- $\kappa \mathrm{B}$ pathway is important to promote the secretion of IL- 1 , IL- 6 , IL- 8 , and TNF- $\alpha$ and could sever as a transcriptional regulator for recruiting macrophages and monocytes, we detected levels of MAPK and NF- $\kappa$ B in AS mice. The results displayed decreased levels of MAPK and NF- $\kappa B$ in ApoE-/- mice (Figure 6A, 6B) (all $p<0.05$ ).

Subsequently, the mRNA and protein levels of MAPK and NF- $\kappa \mathrm{B}$ in oxLDL-treated HA-VSMCs were determined by qRT-PCR and Western blot analysis, and elevated levels of MAPK and NF- $\kappa$ B (Figure 6C) $(\mathrm{p}<0.05)$, and decreased levels of MAPK and NF- $\kappa B$ were observed in the oxLDL + si-PVT1-treated cells (Figure 6D) $(\mathrm{p}<0.05)$. These results confirmed that silencing PVT1 downregulates the MAPK/NF- $\kappa \mathrm{B}$ signaling pathway in oxLDL-treated HA-VSMCs and AS mice.

\section{Silencing PVT1 suppresses AS progression via downregulating the MAPK/NF- $\kappa$ B pathway}

The aforementioned data unraveled that silencing PVT1 downregulated the MAPK/NF- $\kappa \mathrm{B}$ pathway. Moreover, the inactivation of the MAPK/NF- $\kappa B$ pathway suppresses AS development [19-21]. To further confirm the effect of PVT1 on AS via the MAPK/NF- $\kappa$ B pathway, we added
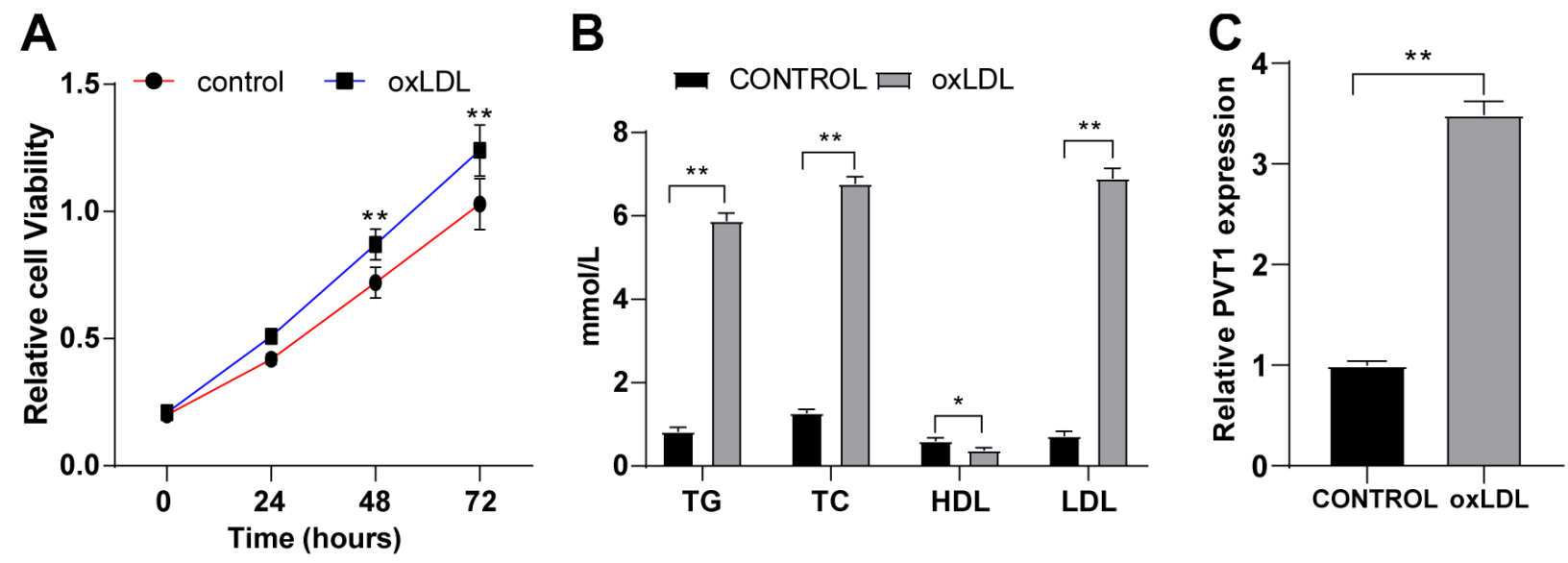

Figure 3. PVT1 is highly expressed in oxLDL-treated HA-VSMCs. HA-VSMCs were treated with $50 \mathrm{mg} / \mathrm{mL}$ ox $L D L$ for $24 \mathrm{hr}$. (A) Cell viability detected by MTT assay; (B) Levels of TG, TC, HDL, and LDL detected by ELISA; (C) LncRNA PVT1 relative expression detected by qRTPCR. $\mathrm{N}=3$. Data were presented as mean \pm standard deviation. Pairwise comparisons were analyzed using independent sample $t$ test. $* p<$ $0.05, * * p<0.01$. PVT1, plasmacytoma variant translocation 1; ox LDL, oxidative low density lipoprotein; HA-VSMCs, Human arterial vascular smooth muscle cells. 
a specific inhibitor of MAPK, U0126, to oxLDLtreated HA-VSMCs after PVT1 overexpression. The results showed that the cell viability, cell clones and EdU positive rates of HA-VSMCs were noticeably downregulated afterwards (Figure 7A-7C) (all p < 0.05). The apoptotic cells and G2/M-phase cells were augmented while $\mathrm{S}$-phase cells were reduced (Figure 7D, 7E) ( $<<0.05)$. Western blot analysis exhibited an increase in levels of cleaved caspase-3, PARP and cleaved caspase-9 (Figure 7F) (all $\mathrm{p}<0.05$ ). The abovementioned results ascertained that silencing
PVT1 suppresses AS development by downregulating the MAPK/NF- $\kappa \mathrm{B}$ pathway.

\section{DISCUSSION}

Recognized as a common malignant disease of the vessel wall and a chronic inflammatory process, AS contributes to increased morbidity and mortality rates for patients with cardiovascular and cerebrovascular diseases, and is still a global burden with increasing incidence in developing countries [22]. LncRNAs exert
A

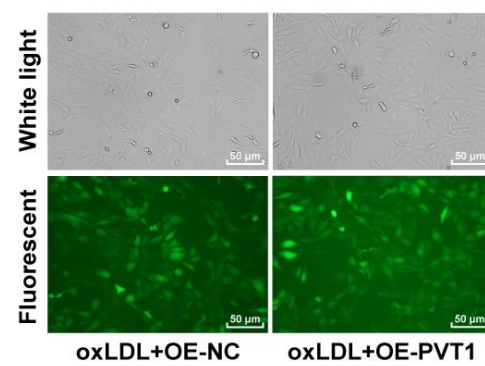

C

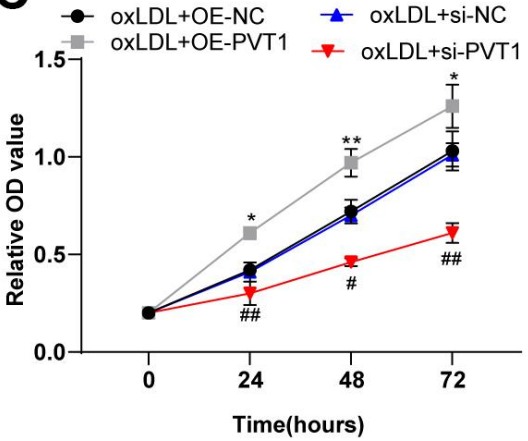

E

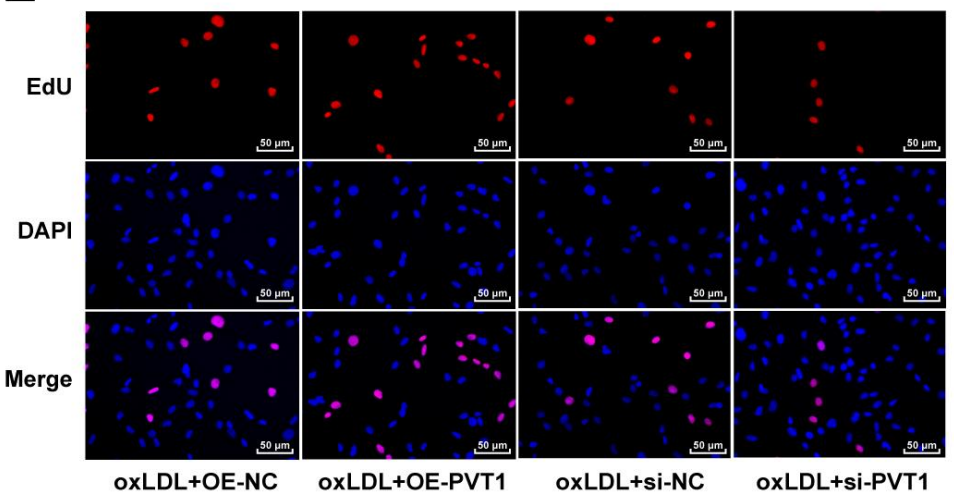

B

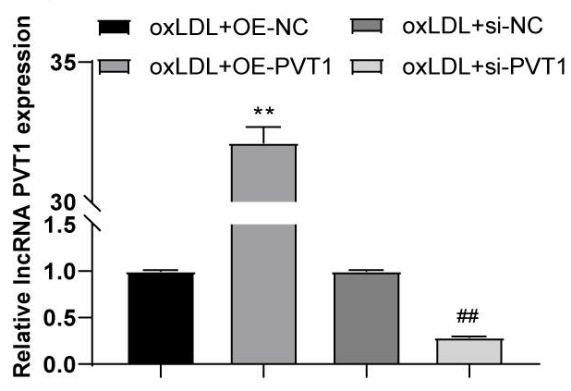

D
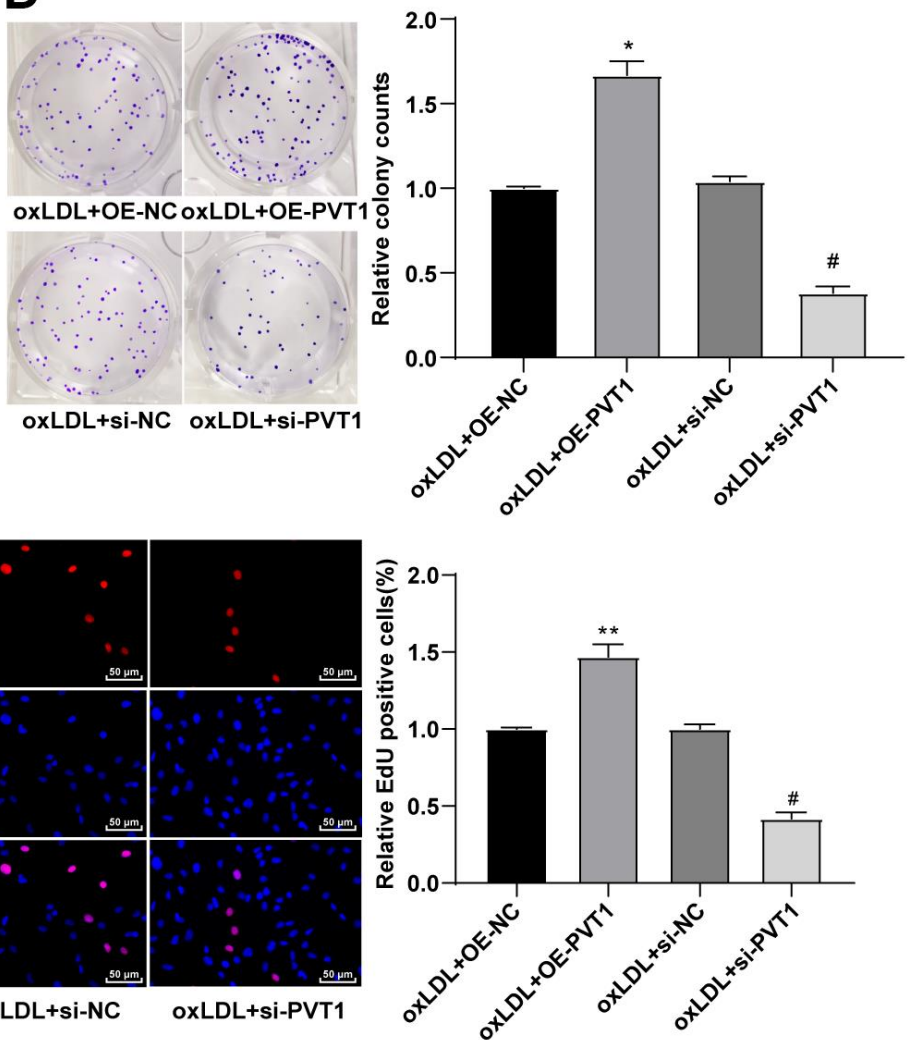

Figure 4. Silencing PVT1 induced by siRNA inhibits the activity and proliferation of HA-VSMCs. (A) Fluorescence of GFP ensures the recombinant plasmid was transfected properly; (B) Relative expression of PVT1 detected by qRT-PCR; (C) Cell viability measured by MTT assay; (D) Cell colony formation ability detected by colony formation assay; (E) DNA replication activity detected by EdU assay. Compared to the oe-NC group, $* p<0.05, * * p<0.01$; compared to the si-NC group, $\# p<0.05, \# \# p<0.01$. PVT1, plasmacytoma variant translocation 1 ; HA-VSMCs, Human arterial vascular smooth muscle cells; oe, overexpression; NC, negative control. 
essential functions on vascular inflammatory response and metabolism in endothelial cells and macrophages, suggestive of the possible effects of lncRNAs on AS development [23]. Thus, we studied the mechanism of lncRNA PVT1 in AS progression with the MAPK/ NF- $\kappa$ B pathway involved. Collectively, we found that silencing PVT1 suppressed AS progression by downregulating the MAPK/NF- $\mathrm{\kappa B}$ signaling pathway.

The first chief result of the current study was that IncRNA PVT1 was highly expressed in the serum of AS patients, ApoE-/-mice and oxLDL-treated HA-VSMCs, which was in consistency with a previous study [9]. The unfavorable role of PVT1 was further identified in other diseases. For instance, increased expression of PVT1 was found in hippocampus tissues of epileptic rats and was associated with neuronal loss and inflammation [24].

PVT1 expression was increased in acute ischemic stroke patients [25], atrial fibrosis patients [26] and patients with cardiomyocyte toxicity [27]. Besides, we found silencing PVT1 reduced levels of TG, TC, HDL
A
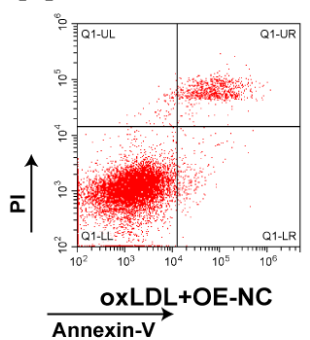

B

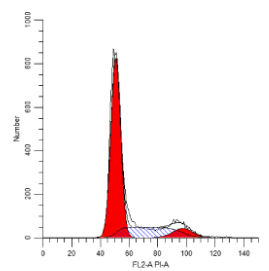

oxLDL+OE-NC

C

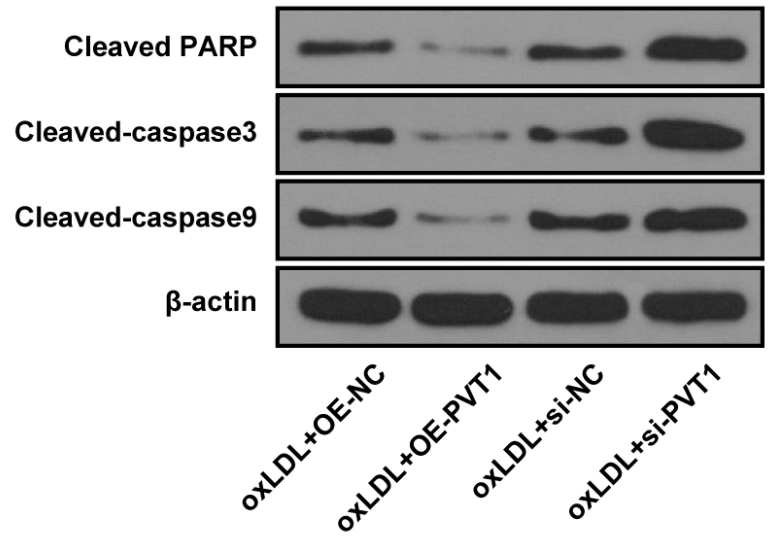

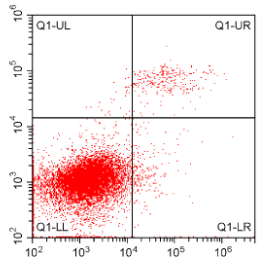

oxLDL+OE-PVT1

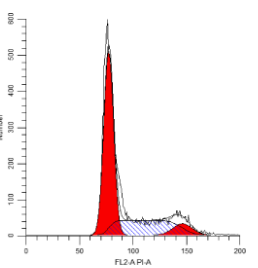

oxLDL+OE-PVT1

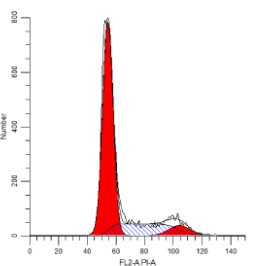

oxLDL+si-NC

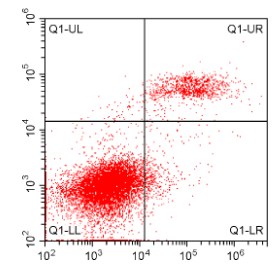

oxLDL+si-NC

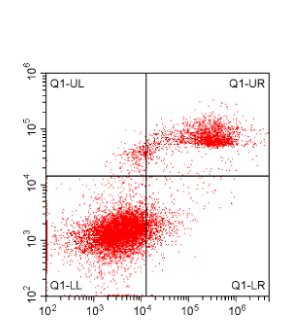

oxLDL+si-PVT1
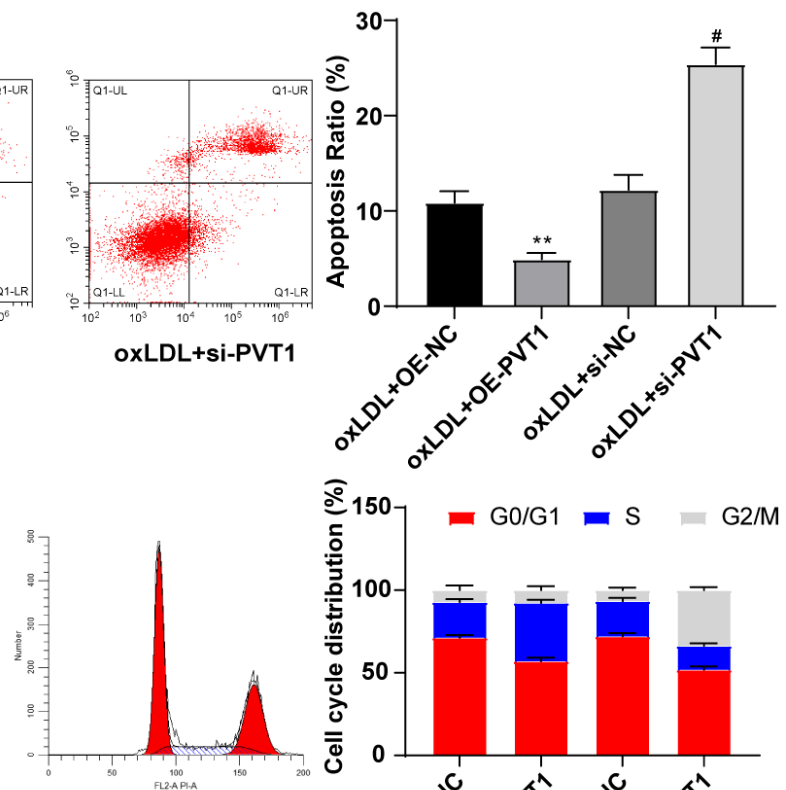

oxLDL+si-PVT1

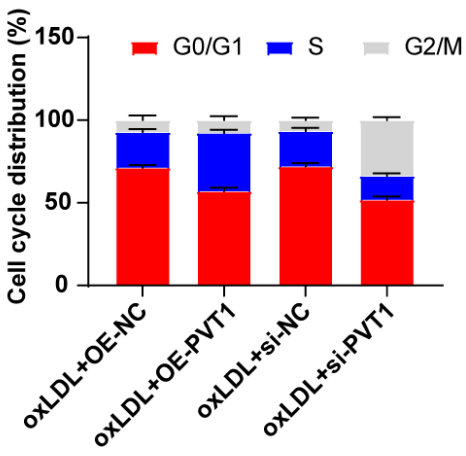

$40 \mathrm{kDa}$

$17 \mathrm{kDa}$

$42 \mathrm{kDa}$

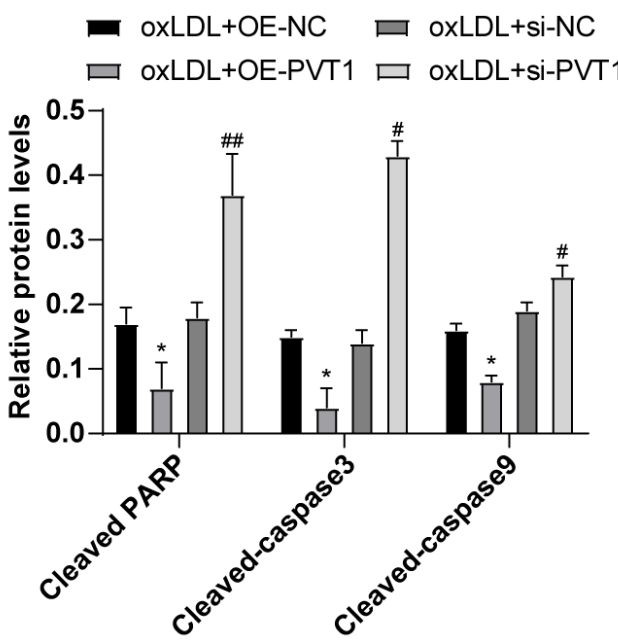

Figure 5. Silencing PVT1 promotes apoptosis and cell cycle arrest of HA-VSMC. (A) Relative apoptosis rate of HA-VSMCs detected by flow cytometry; (B) Relative cell cycle distribution of HA-VSMCs; (C) Relative levels of apoptosis-related proteins detected by Western blot; compared to the oe-NC group, ${ }^{*} p<0.05, * * p<0.01$; compared to the si-NC group, $\# p<0.05$, \#\# $p<0.01$. PVT1, plasmacytoma variant translocation 1; HA-VSMCs, human arterial vascular smooth muscle cells; oe, overexpression; NC, negative control. 
and LDL, MMP-2, MMP-9, CRP, and levels of inflammation-related factors, but increased TIMP expression. AS is considered as an inflammatory disease and lipid metabolism disorder [28]. MMPs are related to AS progression [29]. CRP, the representative acute phase protein, is sensitive for inflammation and tissue damage, and its elevated plasma level is correlated with increased risk of cardiovascular diseases [30]. si-PVT1 diminished levels of TNF- $\alpha$, IL- 6 and IL- $1 \beta$ in lipopolysaccharideinduced HK-2 cells, thus alleviating inflammation and acute kidney injury [31]. Silencing PVT1 downregulates MMP-1 and MMP-9 protein expression and upregulates TIMP-1 in ApoE-/- mice [32]. In addition, a recent study noted that knockdown of PVT1 decreased levels of MMP2 and MMP-9, augmented TIMP-1 expression, and suppressed serum levels of TNF- $\alpha$, IL- $1 \beta$, and IL- 6 in VAMC and ApoE-/- mice of abdominal aortic aneurysm model [32]. Altogether, silencing PVT1 could attenuate AS damage.

Moreover, the data obtained in this study confirmed that silencing PVT1 inhibited HA-VSMC viability, proliferation and promoted apoptosis and cell cycle arrest, presenting by elevated cleaved caspase-3, PARP, and cleaved caspase-9. The cleavage and activation of caspase-3, known as a key effector protease, in apoptotic process cleaves PARP, which serves as an apoptotic biomarker [33]. Silencing PVT1 increases expressions of Bax and cleaved caspase-3 and thus inhibits apoptosis in diabetic nephropathy [34]. LncRNA PVT1 promoted MMP production and facilitated extracellular matrix degradation, leading to VSMC apoptosis and the formation of abdominal aortic aneurysm [32]. PVT1 depletion impaired cell growth and migration ability of vascular endothelial cells [35]. PVT1 knockdown could induce apoptosis in lipopolysaccharide-induced H9c2 cells, through up-regulating Bax and caspase-3 and down-regulating $\mathrm{Bcl}-2$, thereby exerting functional roles in sepsis-induced myocardial depression [36].

Furthermore, to confirm the relationship between PVT1 and the MAPK/NF- $\mathrm{KB}$ pathway, we added a specific inhibitor of MAPK, U0126 to ${ }_{\text {ox }} \mathrm{LDL}$-induced VSMCs after PVT1 overexpression. NF- $\mathrm{KB}$ is considered as a
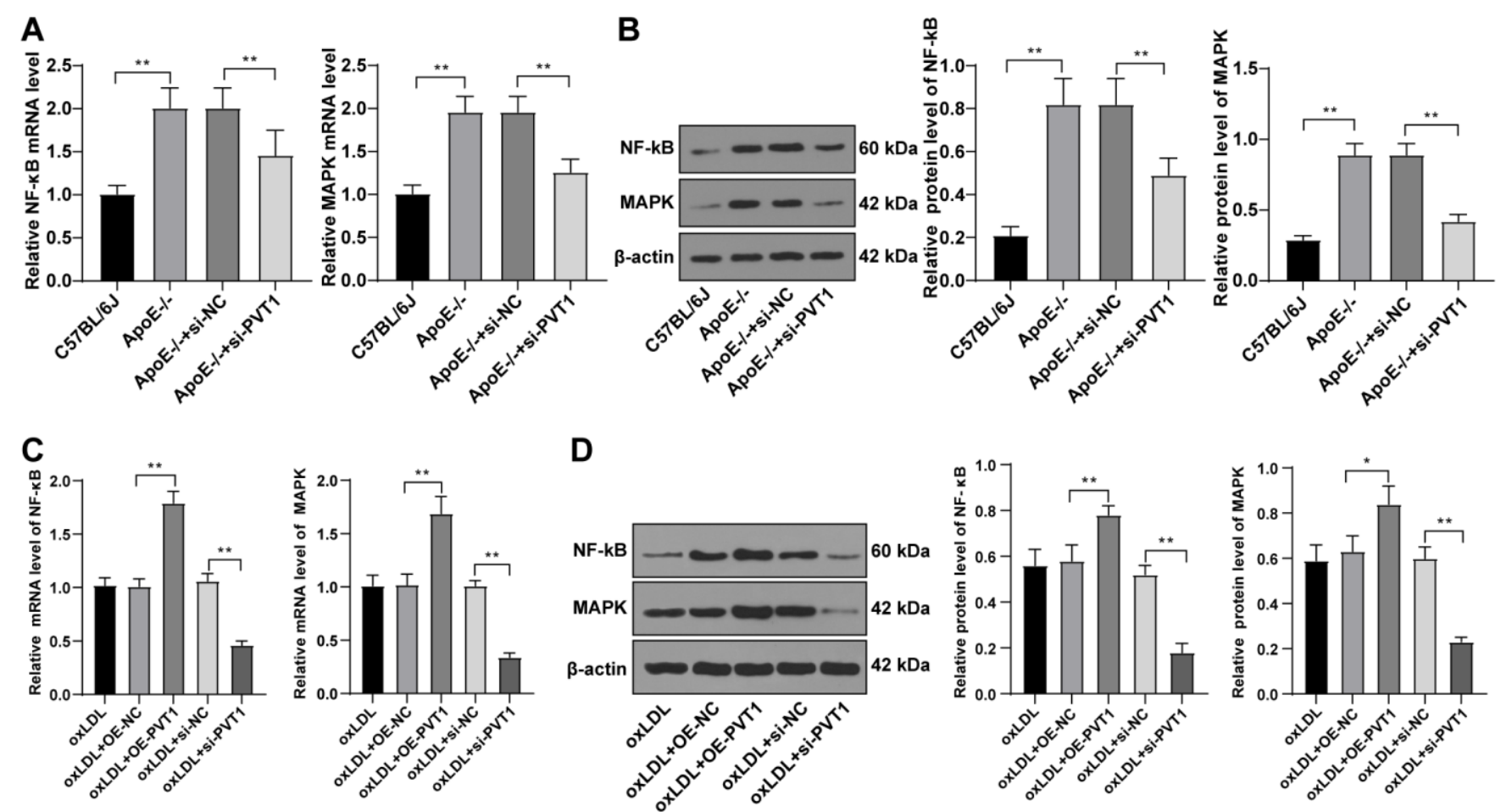

Figure 6. Silencing PVT1 downregulates the MAPK/NF-KB signaling pathway in ox LDL-induced HA-VSMCs and AS mice. (A) mRNA expression of MAPK and NF-KB in AS mice detected by qRT-PCR; (B) Protein levels of MAPK and NF-KB in AS mice detected by Western blot; (C) mRNA expression of MAPK and NF-KB in ox LDL-treated HA-VSMCs detected by qRT-PCR; (D) Protein levels of MAPK and NF-KB in ox LDL treated HA-VSMCs detected by Western blot. Compared to the oe-NC group, $* p<0.05, * * p<0.01$; compared to the si-NC group, \#p<0.05, $\# \#$ < 0.01. PVT1, plasmacytoma variant translocation 1; MAPK, mitogen-activated protein kinase; NF-KB, Nuclear factor-kappa B; oxLDL, oxidative low density lipoprotein; AS, atherosclerosis; HA-VSMCs, Human arterial vascular smooth muscle cells; oe, overexpression; NC, negative control. 
pro-atherogenic factor, mainly due to its regulatory effect on pro-inflammatory proteins linked to AS, thus NF- $\kappa \mathrm{B}$ inhibition could attenuate the pathogenesis of AS [37]. The LOX-1/p38 MAPK pathway participates in endothelial dysfunction in AS [38]. PVT1 was upregulated in the myocardial tissues of sepsis rats, activated the MAPK/NF- $\mathrm{B}$ pathway, and thus inhibited cardiac function and promoted the secretion of inflammatory factors [18]. A previous study verified that another IncRNA, MALAT1 enhances oxLDLinduced autophagy of macrophages in AS by diminishing the expressions of MAPK and NF- $\kappa B$ in AS [39]. We finally came to a conclusion that the protective role of siRNA induced lncRNA PVT1 suppression in AS was achieved via the downregulation of MAPK/NF- $\kappa$ B pathway.

To conclude, these results illustrated that silencing PVT1 inhibited AS induced by high-fat diet in ApoE-/mice, and limited HA-VSMC viability and proliferation and promoted apoptosis and cell cycle arrest, alleviated inflammation, and reduced liposome deposition via suppressing the MAPK/NF- $\mathrm{BB}$ pathway. The findings indicate that silencing lncRNA PVT1 could be a potential strategy to prevent and treat AS. LncRNA PVT1 is an independent hazard factor influencing the

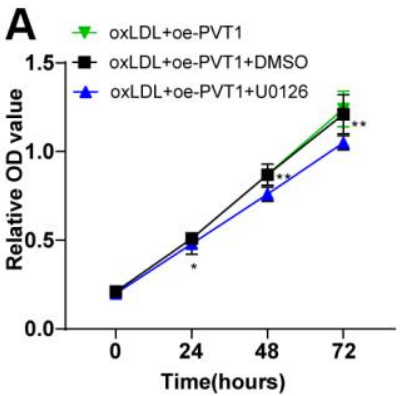

B
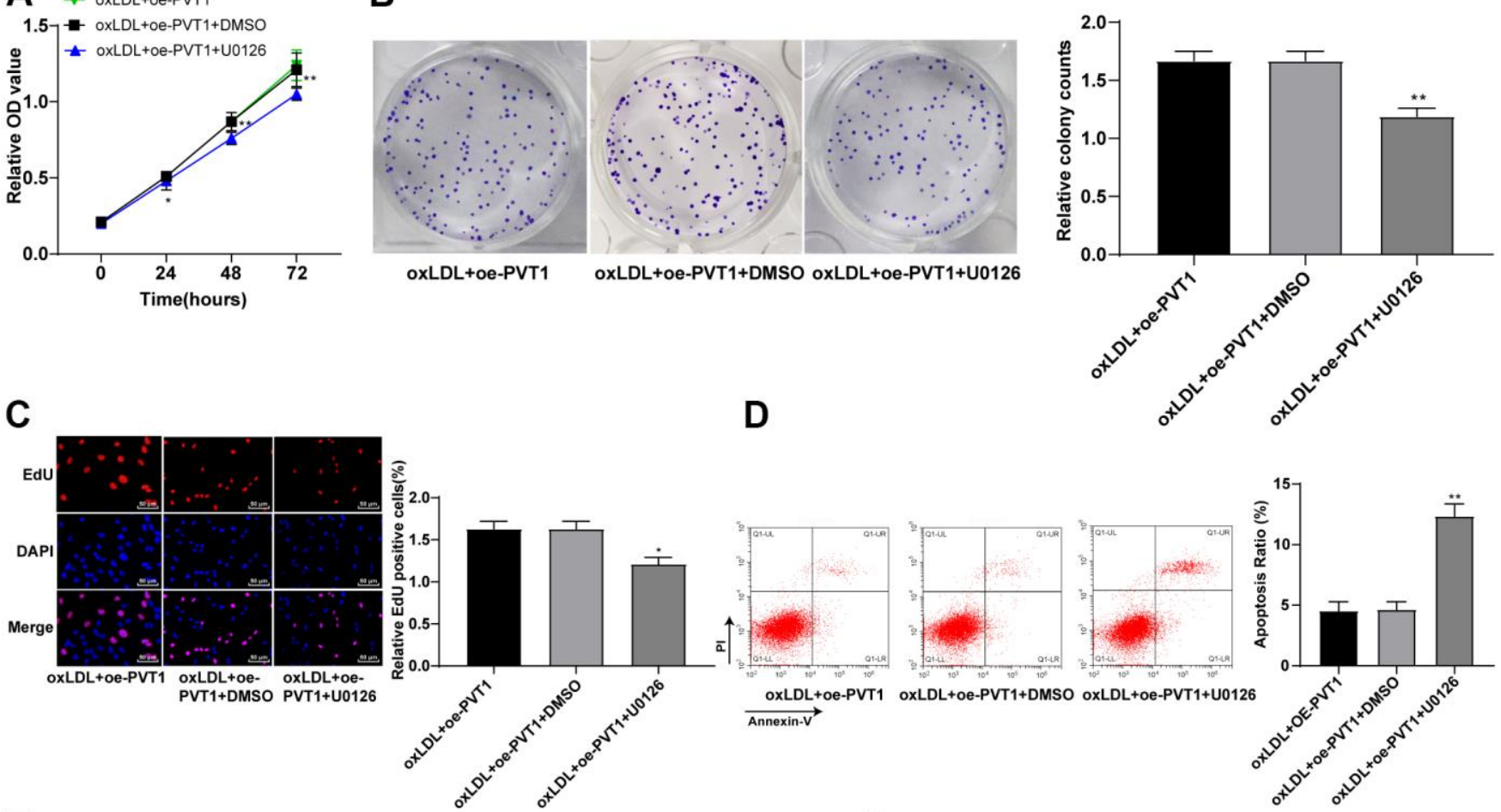

D
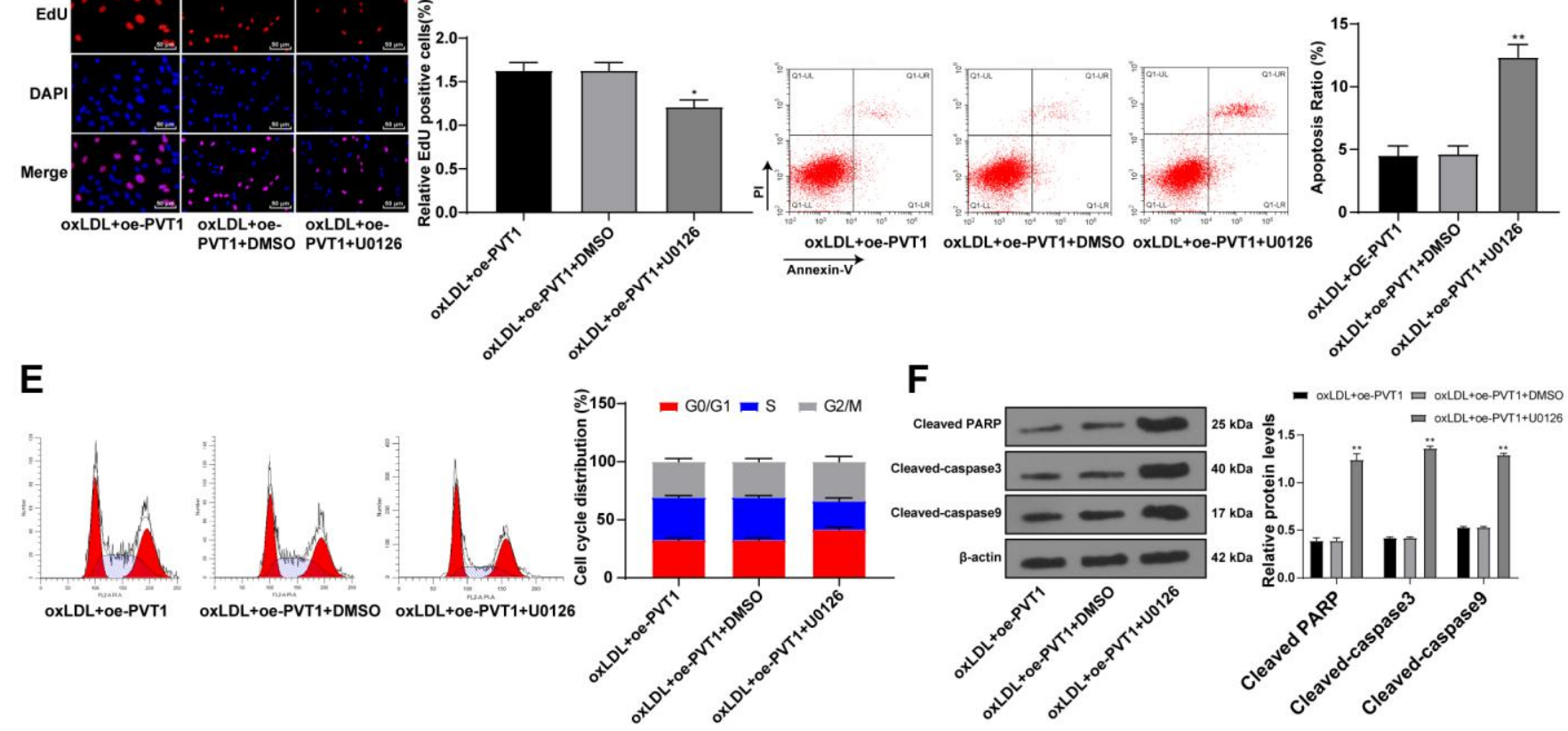

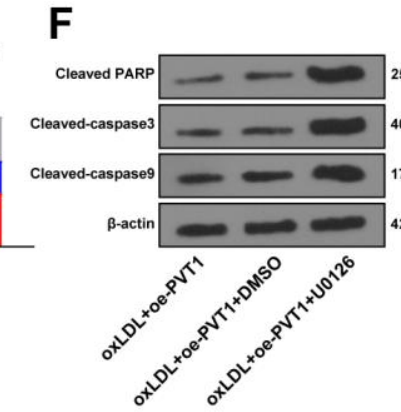

E

Figure 7. Silencing PVT1 suppresses AS progression via downregulating the MAPK/NF-kB signaling pathway. (A) Cell viability measured by MTT assay; (B) Relative cell clones measured by colony experiment; (C) Relative EdU positive rates detected by EdU assay; (D) Relative apoptosis ratio detected by flow cytometry; (E) Relative cell cycle distribution; (F) Relative protein levels of cleaved caspase-3, PARP and cleaved caspase-9 detected by Western blot. Compared to the PVTI-DMSO group, $* p<0.05, * * p<0.01$. PVT1, plasmacytoma variant translocation 1; AS, atherosclerosis; MAPK, mitogen-activated protein kinase; NF-kB, Nuclear factor-kappa B; OD, optical value; EdU, 5ethynyl-2'-deoxyuridine; PARP, PARP, poly(ADP-ribose) polymerase; DMSO, dimethyl sulfoxide. 
coronary AS [9] and is highly expressed in AS patients. The innovation of this study is that we explored the protective effect of siRNA silencing lncRNA PVT1 on anti-AS at molecular, cellular and animal levels by investigating the mechanism of lncRNA PVT1 in AS and the regulation of IncRNA PVT1 on the MAPK/NF$\kappa \mathrm{B}$ pathway, and thus providing new insights into further understanding of the AS pathology and reference for new prevention and treatment strategies for AS and AS-related diseases. Further study should be conducted to find out the possible applicable approaches for AS on the basis of the obtained results in this study.

\section{Limitations}

This study revealed that lncRNA PVT1 participates in AS development and is associated with the MAPK/NF/kB pathway, and investigated the protective effect of siRNA silencing lncRNA PVT1 against AS at molecular, cellular and animal level. However, the MAPK/ NF/kB signaling pathway is a complex cellular pathway. The specific regulatory mechanism of lncRNA PVT1 in the MAPK/NF- $\kappa B$ pathway in AS remains unclear. Additionally, the in vivo study of PVT1 overexpression on AS and the MAPK/NF- $\kappa B$ pathway requires further investigation in future studies.

\section{Future directions}

Further study should be conducted to probe into the specific regulatory mechanism of lncRNA PVT1 in the MAPK/NF- $\mathrm{BB}$ pathway in $\mathrm{AS}$, the in vivo study of PVT1 overexpression on AS and the MAPK/NF- $\mathrm{BB}$ pathway, and possible applicable approach for AS based on results obtained from this study.

\section{MATERIALS AND METHODS}

\section{Ethical statement}

This study was carried out under the approval and supervision of the ethics committee of the Second Hospital of Hebei Medical University. All participants were informed of the study and signed the written consent. Major efforts were made to reduce the animals used and individual suffering.

\section{Sample collection}

Totally 52 serum samples from AS patients who received diagnosis and treatment in the Second Hospital of Hebei Medical University and 38 serum samples from healthy males (aged 38 74 years old; average age: $59.5 \pm 10.4$ ) from April 2017 to September 2018 were enrolled. Inclusion criteria were: (a) all patients were diagnosed with AS, which was confirmed by measuring various indicators; (b) no patients received any treatment; (c) all patients possessed complete clinical data. Patients were excluded if they were complicated with chronic system diseases or other malignancies.

\section{Construction of human recombinant PVT1 lentivirus vector and small interfering RNA PVT1 lentivirus vector}

The lentivirus vector pLVX-IRES-ZsGreen1 containing the green fluorescent protein (GFP) reporter gene was procured from (Clontech Laboratories, Inc., Palo Alto, CA, USA). The complementary DNA (cDNA) of human lncRNA PVT1 was synthesized by Sangon Biotech Co., Ltd. (Shanghai, China). PCR amplification was performed with cDNA as the template. The amplified PVT1 sequence was cloned into the pLVXIRES-ZsGreen1 vector to obtain the pLVX-PVT1IRES-ZsGreen1 plasmid, named as the lncRNA PVT1 plasmid and the empty vector pLVX-IRES-ZsGreen1.

The lentivirus-constructed siRNA LV-PVT1-RNAi-1 expression vector and hU6-MCS-Ubiquitin-EGFPIRES-puromycin as the non-targeting control lentiviral vector were synthesized by Genechem (Shanghai, China), and recorded as si-PVT1 and si-negative control (NC), respectively.

\section{Cell culture}

Human arterial vascular smooth muscle cells (HAVSMCs; Shanghai Institutes for Biological Sciences, the Chinese Academy of Sciences, Shanghai, China) were cultured for $48 \mathrm{~h}$ in the Roswell Park Memorial Institute (RPMI)-1640 medium (Gibco Company, Grand Island, NY, USA) containing $10 \%$ fetal bovine serum (FBS) and F-12K medium (Gibco Company) at $37^{\circ} \mathrm{C}$ and 5\% CO2. Upon 80\% 90\% confluence, cells were detached using $0.025 \%$ trypsin (Gibco Company) and passaged.

\section{Cell transfection and grouping}

Well-grown HA-VSMCs were seeded in 6-well plates at the density of $5 \times 106$ cells/well and then assigned into 8 groups: 1) oxLDL group [HA-VSMCs were induced by $10 \mu \mathrm{g} / \mathrm{mL}$ (final concentration) oxidative low density lipoprotein (oxLDL; AY-1501, AngYuBio, Shanghai, China) and cultured for $48 \mathrm{~h}]$, 2) control group (HA-VSMCs were cultured with an equal amount of normal saline for $48 \mathrm{~h}$ ), 3) oxLDL + si-NC group (oxLDL-induced HA-VSMCs were cultured for $48 \mathrm{~h}$ after transfecting with si-NC using Lipofectamine 3000 kit), 4) oxLDL + si-PVT1 group (oxLDL-induced HAVSMCs were cultured for $48 \mathrm{~h}$ after transfecting with 
si-PVT1), 5) oxLDL + oe-NC group (oxLDL-induced HA-VSMCs were cultured for $48 \mathrm{~h}$ after transfecting with oe-NC), 6) oxLDL + oe-PVT1 group (oxLDLinduced HA-VSMCs were cultured for $48 \mathrm{~h}$ after transfecting with oe-PVT1), 7) oxLDL + oe-PVT1 + U0126 group (oxLDL-induced HA-VSMCs were cultured for $48 \mathrm{~h}$ after transfecting with oe-PVT1 and adding $10 \mathrm{ng} / \mathrm{mL}$ MAPK-specific inhibitor U0126), and 8) oxLDL + oe-PVT1 + DMSO group (oxLDL-induced HA-VSMCs were cultured for $48 \mathrm{~h}$ after transfecting with oe-PVT1 and adding $10 \mathrm{ng} / \mathrm{mL}$ DMSO).

\section{Establishment of AS mouse model}

Specific pathogen-free (SPF) male apolipoprotein E knockout (ApoE-/-) mice in pure C57BL/6 background and wild C57BL/6 mice (weighing 20 30 g, aged 8 10 weeks; Beijing Vital River Laboratory Animal Technology Co., Ltd, Beijing, China) were fed in a SPF animal laboratory with 50 60\% humidity at $22 \sim 25^{\circ} \mathrm{C}$. After mice were adaptively fed for 7 days, mice were assigned in 4 groups $(\mathrm{N}=8)$ : 1) the normal control group (wild C57BL/6 mice were fed with conventional diet (5\% fat) for 10 weeks), 2) the AS group [ApoE-/mice were fed with high-fat diet $(21 \%$ fat, $0.15 \%$ cholesterol) for 10 weeks], 3) the si-NC group (ApoE-/mice were immediately injected with $75 \mu \mathrm{g} / \mathrm{kg}$ si-NC via the tail vein after feeding with high-fat diet for 10 weeks), and 4) the si-PVT1 group (ApoE-/- mice were immediately injected with $75 \mu \mathrm{g} / \mathrm{kg}$ si-PVT1 after feeding with high-fat diet for 10 weeks). Mice received two injections in the 1st week and then one injection per week for 3 weeks. The mice were executed afterwards.

One day before the mice were executed, no water or food was provided. The serum of 8 mice in each group was extracted from the orbital vein for enzyme-linked immunosorbent assay (ELISA). Five mice were selected from each group and the distal portions of the ascending aortas, aortic arches, and descending aortas down to the iliac bifurcations were extracted for oil red $\mathrm{O}$ staining. The aortas of the rest three mice in each group were used for immunohistochemistry.

\section{ELISA}

The levels of tumor necrosis factor- $\alpha$ (TNF- $\alpha$ ), interleukin (IL)-6, IL-1 $\beta$, total cholesterol (TC), total triglyceride (TG), low density lipoprotein (LDL) and high density lipoprotein (HDL) were measured using IL-6 ELISA kit (IB-E10049, IBIO, Shenzhen, China), IL-1 $\beta$ ELISA kit (SEA563Ov03, SHRBIO, Nanjing, China), TNF- $\alpha$ ELISA kit (BEK-2101-1P, Biosensis, Termecula, CA, USA), TG ELISA kit (CEB687Ge02, SHRBIO), TC ELISA kit (1531142776, Jianglai, Shanghai, China), HDL ELISA kit (SEB006Hu03,
SHRBIO) and LDL ELISA kit (E03944, WKSUBIO, Shanghai, China) in strict compliance with the instructions.

\section{Immunohistochemistry}

The extracted arterial canals of mice were routinely embedded in paraffin and dewaxed. Each section was sliced into five equal parts. Sections were rinsed with phosphate-buffered saline (PBS) thrice and instilled with $3 \% \mathrm{H} 2 \mathrm{O} 2$ before maintaining for $15 \mathrm{~min}$ at room temperature. After 3 PBS rinses, the sections were instilled with normal goat serum blocking fluid, and maintained for $15 \mathrm{~min}$ at room temperature. Afterwards, the sections were incubated at $4^{\circ} \mathrm{C}$ overnight with 50 $\mu \mathrm{L}$ rabbit anti-human $\mathrm{CD68}$ antibody (1:8,000; ab213363; Abcam Inc., Cambridge, MA, USA). After 3 PBS rinses, the sections were incubated at $37^{\circ} \mathrm{C}$ for 15 min with secondary antibody. Following 3 PBS rinses, the sections were instilled with $40 \mu \mathrm{L}$ horseradish peroxidase-labeled streptavidin-working solution, followed by 15 -min incubation at $37^{\circ} \mathrm{C}$. The sections were again rinsed with PBS thrice, visualized with 2, 4diaminobutyric acid, and counterstained with hematoxylin for $30 \mathrm{~s}$ after rinsing with distilled water, and sealed with neutral gum after dehydrating. Next, 5 visual fields with no overlaps in each section were selected to be observed under the microscope. The cells with brown-yellow- or brown-granules-stained nucleus represented CD68-positive cells. Meanwhile, 5 regions in each section were randomly selected to calculate the positive cells expressing CD68 protein.

\section{Oil red O staining}

After mouse euthanasia, the distal portions of ascending aortas, aortic arches, and the distal parts from descending aortas down to the iliac bifurcations of mice in each group were extracted and laid flat on the white wax surface. Then, the samples were fixed with $10 \%$ (volume/volume) buffered formalin solution overnight, stained for $1 \mathrm{~h}$ with freshly-prepared filtered oil red $\mathrm{O}$ solution, and then rinsed twice with $78 \%$ methanol. The tissues were subsequently fixed on the slides and scanned with ScanScope slide scanning system (Nikon, Melville, NY, USA). Finally, the entire surface areas and oil red O-positive atherosclerotic lesion areas were scanned using Sigma Scan Pro software (SPSS Science, Chicago, IL, USA).

Well-grown cells at the logarithmic growth phase were cultured in the 6-well culture plates at $1 \times 106$ cells/well. When cell confluence reached $70 \%$, the cells were rinsed thrice with PBS, fixed for 1 min with 50\% isopropanol, and stained for $10 \mathrm{~min}$ with oil red $\mathrm{O}$ staining solution. Following 5-min hematoxylin 
staining, the red cells were observed and counted under the microscope to calculate the ratio of oil red $\mathrm{O}$ staining areas.

\section{Flow cytometry}

After PBS washing and $0.025 \%$ trypsin digestion, the cells in good growing conditions were treated for $24 \mathrm{~h}$ at $-20^{\circ} \mathrm{C}$ with $70 \%$ methanol (v/v) and then treated for $20 \mathrm{~min}$ with $50 \mu \mathrm{g} / \mathrm{mL}$ propidium iodide (PI) containing $10 \mu \mathrm{g} / \mathrm{mL}$ RNase. Finally, the flow cytometer was used to detect cell cycle distribution.

After addition with $5 \mu \mathrm{L}$ Annexin V-fluorescein isothiocyanate and PI, the cell suspension was cultured for $10 \mathrm{~min}$ in the dark. Cell apoptosis was then detected after staining using the flow cytometer.

\section{5-Ethynyl-2'-deoxyuridine (EdU) assay}

The DNA replication ability of the well-grown cells was detected by a Cell-light EdU fluorescence kit (RiboBio, Guangdong, China). The cells were treated according to the provided instructions of the EdU kit. Five visual fields were randomly photographed under a FSX100 fluorescence microscope (Olympus Optical Co., Ltd, Tokyo, Japan). Blue fluorescence indicated all cells, whereas red fluorescence represented the replicating positive cells infiltrated by EdU. The percent of EdUpositive cells was then computed.

\section{Colony formation assay}

HA-VSMCs of the P3 generation in good conditions were treated with $0.025 \%$ trypsin and then seeded in 6well plates at 1000 cells/well. After 14-day culture at $37^{\circ} \mathrm{C}$ with $5 \% \mathrm{CO} 2$, the cells were treated for $30 \mathrm{~min}$ with $75 \%$ methanol, then stained with $0.2 \%$ crystal violet and then the number of clones was counted. Each experiment was independently conducted 3 times.

\section{3-(4, 5-dimethylthiazol-2-yl)-2, 5-diphenyltetrazolium bromide (MTT) assay}

The cells were digested by trypsin and made into singlecell suspension at the concentration of $1 \times 104$ cells $/ \mathrm{mL}$ by RPMI 1640 medium supplemented with $10 \%$ FBS. After mixing, $200 \mu \mathrm{L}$ single-cell suspension $(2 \times 103$ cells/well $)$ were supplemented into each well of the 96-well plate. The blank wells were left for zero setting, and were added only culture medium without cells, serving as controls. Five duplicated wells were set up in each group. Following inoculation, the cells were cultured for $0 \sim 7$ days in an incubator $\left(37^{\circ} \mathrm{C}, 5 \% \mathrm{CO} 2\right)$. After $0,24,48$ and $72 \mathrm{~h}$ of culture, $20 \mu \mathrm{L} 5 \mathrm{mg} / \mathrm{mL}$ MTT solution was added to each well, and cultured again for $4 \mathrm{~h}$ before discarding the supernatant. Afterward, $200 \mu \mathrm{L}$ dimethyl sulfoxide was supplemented to each well, followed by 10-min vibration so that crystals were fully dissolved. The optical value at $490 \mathrm{~nm}$ was detected.

\section{Quantitative real-time polymerase chain reaction (qRT-PCR)}

The total RNA was obtained from cells and clinical samples using the RNAiso Plus (TaKaRa, Otsu, Shiga, Japan) and Trizol LS Reagent (TaKaRa), respectively. Then the reliability of the obtained RNA was verified by formaldehyde denaturation electrophoresis. Reverse transcription was performed using the PrimeScript ${ }^{\mathrm{TM}}$ RT Reagent Kit (TaKaRa) based on the instructions. The quantification of mRNA expressions was performed by standard real-time-PCR protocol with SYBR Premix Ex Taq (TaKaRa). Glycer aldehyde-3-phosphate dehydrogenase (GAPDH) served as a reference gene and the primers are exhibited in Table 1.

\section{Western blot analysis}

The total protein was extracted using radioimmunoprecipitation assay lysis buffer containing phenylmethylsulfonyl fluoride (Beyotime, Shanghai, China) and protein levels in the serum were determined using the bicinchoninic acid kit. Next, an equal amount $(50 \mathrm{mg})$ of protein was loaded into $10 \%$ sodium dodecyl sulfate polyacrylamide gel electrophoresis, and then moved onto polyvinylidene fluoride (PVDF) membranes (Millipore, Billerica, MA, USA) which were subsequently incubated at room temperature with tris-buffered saline tween (Boster, Wuhan, Hubei, China) containing 5\% skim milk for the prevention of nonspecific binding. Afterward, the membranes were incubated at $4^{\circ} \mathrm{C}$ overnight with primary antibodies (all from Abcam) (Table 2), and subsequently with rabbit anti-rat secondary antibody for $1 \mathrm{~h}$ at room temperature. The protein was developed with an enhanced chemiluminescence reagent and visualized with a BioSpectrum gel imaging system (Bio-Rad, Hercules, CA, USA).

\section{Statistical analysis}

SPSS 21.0 (IBM Corp., Armonk, NY, USA) was used to process data. The normal distribution of data was verified by Kolmogorov-Smirnov test. The results were depicted in the form of mean \pm standard deviation. Comparisons between two groups were analyzed using the $t$ test, and comparisons among multi groups using the 1-way analysis of variance (ANOVA), followed by Tukey's multiple comparisons test. The counting data were 
Table 1. Primer sequences for qRT-PCR.

\begin{tabular}{|c|c|}
\hline Primer & $\begin{array}{c}\text { Sequence } \\
\end{array}$ \\
\hline lncRNA PVT1-F (human) & CCTGTCACTCCTGCTGTGAA \\
\hline IncRNA PVT1-R (human) & АCССССТTTACCTGCTCACT \\
\hline IncRNA PVT1-F (mouse) & CCCATAACACACGCAATGAG \\
\hline lncRNA PVT1-R (mouse) & TGTTGCATGTGGCATTACCT \\
\hline MAPK-F & GACGAATGGAAGAGCCTGAC \\
\hline MAPK-R & AGATACATGGACAAACGGACA \\
\hline$N F-\kappa B-F$ & TGGGGACTACGACCTGAATG \\
\hline$N F-\kappa B-R$ & GGGGGCACGATTGTCAAAGA \\
\hline MMP-2-F & GTTCCCCTTCTTGTTCAATG \\
\hline MMP-2 -R & CTTGCCATCCTTCTCAAAGT \\
\hline MMP-9-F & CGCAGACATCGTCATCCAGT \\
\hline MMP-9-R & AAGGTCAAGACGTGCCAGAG \\
\hline TIMP-1-F & CCAGCGTTATGAGATCAAGA \\
\hline TIMP-1-R & AGTATCCGCAGACACTCTCC \\
\hline CRP & AGACATGTCGAGGAAGGCTTTT \\
\hline CRP & TCGAGGACAGTTCCGTGTAGAA \\
\hline GADPH-F & ACAGTCAGCCGCATCTTCTT \\
\hline GADPH-R & GACAAGCTTCCCGTTCTCAG \\
\hline
\end{tabular}

Note: qRT-PCR, quantitative real-time polymerase chain reaction; IncRNA PVT1, long non-coding RNA plasmacytoma variant translocation 1; MAPK, mitogen-activated protein kinase; NF-KB, Nuclear factorkappa B; MMP, matrix metalloproteinase; TIMP-1, tissue inhibitor of metalloproteinase-1; CRP, C reactive protein; GAPDH, glyceraldehyde-3-phosphate dehydrogenase; F, forward; R, reversed.

Table 2. Antibodies used in the western blot analysis.

\begin{tabular}{lcc}
\hline Antibodies & Item no. & Dilution ratio \\
\hline MMP-2 & ab37150 & $1: 500$ \\
MMP-9 & $a b 38898$ & $1: 1000$ \\
CRP & $a b 211631$ & $1: 1000$ \\
TIMP-1 & $a b 234662$ & $1: 5000$ \\
MAPK & $a b 185145$ & $1: 1000$ \\
NF-kB & $a b 32360$ & $1: 5000$ \\
Cleaved caspase-3 & $a b 2302$ & $1: 50$ \\
Cleaved caspase-9 & $a b 232$ & $1: 50$ \\
Cleaved PARP & $a b 32064$ & $1: 5000$ \\
$\beta$-actin & $a b 179467$ & $1: 5000$ \\
\hline
\end{tabular}

Note: MMP, matrix metalloproteinase; CRP, $C$ reactive protein; TIMP-1, tissue inhibitor of metalloproteinase-1; MAPK, mitogen-activated protein kinase; NF-KB, Nuclear factor-kappa B; PARP, poly(ADP-ribose) polymerase.

compared using the Fisher's exact test. The $p$-value was procured by a two-tailed test and $p<0.05$ was indicative of significant difference.

\section{Data availability statement}

All the data generated or analyzed during this study are included in this published article.

\section{AUTHOR CONTRIBUTIONS}

H.D. is the guarantor of integrity of the entire study and contributed to the concepts and design of this study. H.D. and R.Y. contributed to the experimental studies and the data acquisition. H.Z. and L.Q. contributed to the data analysis and definition of intellectual content. X.Z. and H.S. contributed to the statistical analysis. 
H.D. took charge of the manuscript preparation and manuscript editing. All authors read and approved the final manuscript.

\section{CONFLICTS OF INTEREST}

The authors declare that they have no conflicts of interest.

\section{FUNDING}

This work was partially supported by 2016 Hebei Province Medical Science Research Key Project (20160528).

\section{REFERENCES}

1. Husain K, Hernandez W, Ansari RA, Ferder L. Inflammation, oxidative stress and renin angiotensin system in atherosclerosis. World J Biol Chem. 2015; 6:209-17.

https://doi.org/10.4331/wjbc.v6.i3.209

PMID:26322175

2. Moore KJ, Tabas I. Macrophages in the pathogenesis of atherosclerosis. Cell. 2011; 145:341-55.

https://doi.org/10.1016/i.cell.2011.04.005

PMID:21529710

3. Tabas I, García-Cardeña G, Owens GK. Recent insights into the cellular biology of atherosclerosis. J Cell Biol. 2015; 209:13-22.

https://doi.org/10.1083/jcb.201412052

PMID:25869663

4. Zarzycka B, Nicolaes GA, Lutgens E. Targeting the adaptive immune system: new strategies in the treatment of atherosclerosis. Expert Rev Clin Pharmacol. 2015; 8:297-313.

https://doi.org/10.1586/17512433.2015.1025052

PMID:25843158

5. Min L, Garbutt C, Tu C, Hornicek F, Duan Z. Potentials of Long Noncoding RNAs (LncRNAs) in Sarcoma: From Biomarkers to Therapeutic Targets. Int J Mol Sci. 2017; 18:731.

https://doi.org/10.3390/ijms18040731

PMID:28353666

6. He R, Hu Z, Wang Q, Luo W, Li J, Duan L, Zhu YS, Luo DX. The role of long non-coding RNAs in nasopharyngeal carcinoma: As systemic review. Oncotarget. 2017; 8:16075-83.

https://doi.org/10.18632/oncotarget.14211 PMID:28039476

7. Liu $\mathrm{Y}$, Zheng L, Wang $\mathrm{Q}$, Hu YW. Emerging roles and mechanisms of long noncoding RNAs in atherosclerosis. Int J Cardiol. 2017; 228:570-82.

https://doi.org/10.1016/j.ijcard.2016.11.182 PMID:27875736
8. Wang L, He JH, Han ZP. Characteristics of PVT1 and its roles in diseases. Chin Med Sci J. 2014; 29:236-38.

https://doi.org/10.1016/s1001-9294(14)60077-8 PMID:25429749

9. Quan W, Hu PF, Zhao X, Lianhua CG, Batu BR. Expression level of IncRNA PVT1 in serum of patients with coronary atherosclerosis disease and its clinical significance. Eur Rev Med Pharmacol Sci. 2020; 24:6333-37.

https://doi.org/10.26355/eurrev 20200621531 PMID: $\underline{32572930}$

10. Simion V, Zhou $H$, Pierce JB, Yang $D$, Haemmig $S$, Tesmenitsky Y, Sukhova G, Stone PH, Libby P, Feinberg MW. LncRNA VINAS regulates atherosclerosis by modulating NF-KB and MAPK signaling. JCl Insight. 2020; 5:e140627.

https://doi.org/10.1172/ici.insight.140627 PMID: $\underline{3021969}$

11. Fann DY, Lim YA, Cheng YL, Lok KZ, Chunduri P, Baik SH, Drummond GR, Dheen ST, Sobey CG, Jo DG, Chen CL, Arumugam TV. Evidence that NF-KB and MAPK Signaling Promotes NLRP Inflammasome Activation in Neurons Following Ischemic Stroke. Mol Neurobiol. 2018; 55:1082-96.

https://doi.org/10.1007/s12035-017-0394-9 PMID:28092085

12. Yousif NG, Hadi NR, Al-Amran F, Zigam QA. Cardioprotective effects of irbesartan in polymicrobial sepsis : The role of the p38MAPK/NF-kB signaling pathway. Herz. 2018; 43:140-45.

https://doi.org/10.1007/s00059-017-4537-6 PMID:28144715

13. Pan JX. LncRNA H19 promotes atherosclerosis by regulating MAPK and NF-kB signaling pathway. Eur Rev Med Pharmacol Sci. 2017; 21:322-28.

PMID:28165553

14. Allahverdian S, Chehroudi AC, McManus BM, Abraham $\mathrm{T}$, Francis GA. Contribution of intimal smooth muscle cells to cholesterol accumulation and macrophage-like cells in human atherosclerosis. Circulation. 2014; 129:1551-59.

https://doi.org/10.1161/CIRCULATIONAHA.113.00501 $\underline{\text { PMID:24481950 }}$

15. Bennett MR, Sinha S, Owens GK. Vascular Smooth Muscle Cells in Atherosclerosis. Circ Res. 2016; 118:692-702.

https://doi.org/10.1161/CIRCRESAHA.115.306361 PMID:26892967

16. Lao KH, Zeng L, Xu Q. Endothelial and smooth muscle cell transformation in atherosclerosis. Curr Opin Lipidol. 2015; 26:449-56. 
https://doi.org/10.1097/MOL.0000000000000219 PMID:26218417

17. Rosenfeld ME, Ross R. Macrophage and smooth muscle cell proliferation in atherosclerotic lesions of WHHL and comparably hypercholesterolemic fat-fed rabbits. Arteriosclerosis. 1990; 10:680-87.

https://doi.org/10.1161/01.atv.10.5.680

PMID:2403295

18. Feng F, Qi Y, Dong C, Yang C. PVT1 regulates inflammation and cardiac function via the MAPK/NF-KB pathway in a sepsis model. Exp Ther Med. 2018; 16:4471-78.

https://doi.org/10.3892/etm.2018.6814

PMID:30546393

19. Feng $M$, Kong SZ, Wang ZX, He K, Zou ZY, Hu YR, Ma H, Li XG, Ye XL. The protective effect of coptisine on experimental atherosclerosis $\mathrm{ApoE}^{-/-}$mice is mediated by MAPK/NF-KB-dependent pathway. Biomed Pharmacother. 2017; 93:721-29.

https://doi.org/10.1016/i.biopha.2017.07.002

PMID:28700976

20. Xu ZR, Li JY, Dong XW, Tan ZJ, Wu WZ, Xie QM, Yang YM. Apple Polyphenols Decrease Atherosclerosis and Hepatic Steatosis in ApoE-/- Mice through the ROS/MAPK/NF-KB Pathway. Nutrients. 2015; 7:7085-105. https://doi.org/10.3390/nu7085324 PMID:26305254

21. Yang L, Chu Y, Wang Y, Zhao X, Xu W, Zhang P, Liu X, Dong $\mathrm{S}, \mathrm{He}$ W, Gao C. siRNA-mediated silencing of Wnt5a regulates inflammatory responses in atherosclerosis through the MAPK/NF-KB pathways. Int J Mol Med. 2014; 34:1147-52.

https://doi.org/10.3892/ijmm.2014.1860

PMID:25050997

22. Chatzidimitriou D, Kirmizis D, Gavriilaki E, Chatzidimitriou M, Malisiovas N. Atherosclerosis and infection: is the jury still not in? Future Microbiol. 2012; 7:1217-30.

https://doi.org/10.2217/fmb.12.87 PMID:23030426

23. Zhou T, Ding JW, Wang XA, Zheng XX. Long noncoding RNAs and atherosclerosis. Atherosclerosis. 2016; 248:51-61.

https://doi.org/10.1016/i.atherosclerosis.2016.02.025

PMID:26987066

24. Zhao T, Ding $Y$, Li M, Zhou C, Lin W. Silencing IncRNA PVT1 inhibits activation of astrocytes and increases BDNF expression in hippocampus tissues of rats with epilepsy by downregulating the Wnt signaling pathway. J Cell Physiol. 2019. [Epub ahead of print].

https://doi.org/10.1002/icp.28264

PMID:30805931
25. Lu J, Xu F, Lu H. LncRNA PVT1 regulates ferroptosis through miR-214-mediated TFR1 and p53. Life Sci. 2020; 260:118305.

https://doi.org/10.1016/i.lfs.2020.118305

PMID:32827544

26. Cao F, Li Z, Ding WM, Yan L, Zhao QY. LncRNA PVT1 regulates atrial fibrosis via miR-128-3p-SP1-TGF- $\beta 1$ Smad axis in atrial fibrillation. Mol Med. 2019; 25:27. https://doi.org/10.1186/s10020-019-0074-5 PMID: $\underline{0894138}$

27. Zhan J, Hu P, Wang Y. IncRNA PVT1 aggravates doxorubicin-induced cardiomyocyte apoptosis by targeting the miR-187-3p/AGO1 axis. Mol Cell Probes. 2020; 49:101490.

https://doi.org/10.1016/i.mcp.2019.101490

PMID:31786333

28. Zhu Y, Xian X, Wang Z, Bi Y, Chen Q, Han X, Tang D, Chen R. Research Progress on the Relationship between Atherosclerosis and Inflammation. Biomolecules. 2018; 8:80.

https://doi.org/10.3390/biom8030080 PMID:30142970

29. Marcos-Jubilar M, Orbe J, Roncal C, Machado FJ, Rodriguez JA, Fernández-Montero A, Colina I, Rodil R, Pastrana JC, Páramo JA. Association of SDF1 and MMP12 with Atherosclerosis and Inflammation: Clinical and Experimental Study. Life (Basel). 2021; 11:414.

https://doi.org/10.3390/life11050414 PMID: $\underline{34062730}$

30. Teupser D, Weber O, Rao TN, Sass K, Thiery J, Fehling $\mathrm{HJ}$. No reduction of atherosclerosis in C-reactive protein (CRP)-deficient mice. J Biol Chem. 2011; 286:6272-79.

https://doi.org/10.1074/ibc.M110.161414

PMID:21149301

31. Huang W, Lan X, Li X, Wang D, Sun Y, Wang Q, Gao H, Yu K. Long non-coding RNA PVT1 promote LPS-induced septic acute kidney injury by regulating TNF $\alpha$ and JNK/NF-KB pathways in HK-2 cells. Int Immunopharmacol. 2017; 47:134-40.

https://doi.org/10.1016/i.intimp.2017.03.030 PMID:28391160

32. Zhang Z, Zou G, Chen X, Lu W, Liu J, Zhai S, Qiao G. Knockdown of IncRNA PVT1 Inhibits Vascular Smooth Muscle Cell Apoptosis and Extracellular Matrix Disruption in a Murine Abdominal Aortic Aneurysm Model. Mol Cells. 2019; 42:218-27.

https://doi.org/10.14348/molcells.2018.0162 PMID:30726659

33. Xu P, Cai X, Zhang W, Li Y, Qiu P, Lu D, He X. Flavonoids of Rosa roxburghii Tratt exhibit radioprotection and anti-apoptosis properties via the $\mathrm{Bcl}-2(\mathrm{Ca}(2+)) /$ 
Caspase-3/PARP-1 pathway. Apoptosis. 2016; 21:1125-43.

https://doi.org/10.1007/s10495-016-1270-1

PMID:27401922

34. Liu DW, Zhang JH, Liu FX, Wang XT, Pan SK, Jiang DK, Zhao ZH, Liu ZS. Silencing of long noncoding RNA PVT1 inhibits podocyte damage and apoptosis in diabetic nephropathy by upregulating FOXA1. Exp Mol Med. 2019; 51:1-15.

https://doi.org/10.1038/s12276-019-0259-6

PMID: $\underline{31371698}$

35. Zheng J, Hu L, Cheng J, Xu J, Zhong Z, Yang Y, Yuan Z. IncRNA PVT1 promotes the angiogenesis of vascular endothelial cell by targeting miR-26b to activate CTGF/ANGPT2. Int J Mol Med. 2018; 42:489-96.

https://doi.org/10.3892/ijmm.2018.3595

PMID:29620147

36. Zhang TN, Goodwin JE, Liu B, Li D, Wen R, Yang N, Xia J, Zhou $\mathrm{H}$, Zhang $\mathrm{T}$, Song WL, Liu CF. Characterization of Long Noncoding RNA and mRNA Profiles in SepsisInduced Myocardial Depression. Mol Ther Nucleic Acids. 2019; 17:852-66. https://doi.org/10.1016/i.omtn.2019.07.020

PMID: $\underline{31472370}$

37. Wang $X$, Chen $Q$, Pu H, Wei $Q$, Duan $M$, Zhang C, Jiang T, Shou X, Zhang J, Yang Y. Adiponectin improves NFKB-mediated inflammation and abates atherosclerosis progression in apolipoprotein E-deficient mice. Lipids Health Dis. 2016; 15:33.

https://doi.org/10.1186/s12944-016-0202-y

PMID:26965176

38. Huang D, Gao W, Lu H, Qian JY, Ge JB. Oxidized lowdensity lipoprotein stimulates dendritic cells maturation via LOX-1-mediated MAPK/NF-KB pathway. Braz J Med Biol Res. 2021; 54:e11062. https://doi.org/10.1590/1414-431X2021e11062 PMID: $\underline{34076144}$

39. Yang J, Lin X, Wang L, Sun T, Zhao Q, Ma Q, Zhou Y. LncRNA MALAT1 Enhances ox-LDL-Induced Autophagy through the SIRT1/MAPK/NF-KB Pathway in Macrophages. Curr Vasc Pharmacol. 2020; 18:652-62. https://doi.org/10.2174/157016111866620031715312 4 PMID: $\underline{32183682}$ 